\title{
Editorial \\ Special Issue on Advances and Technologies in High Voltage Power Systems Operation, Control, Protection, and Security
}

\author{
Hassan Haes Alhelou ${ }^{1, *(D)}$ and Pierluigi Siano ${ }^{2, *(D)}$ \\ 1 Department of Electrical Power Engineering, Tishreen University, Lattakia 2230, Syria \\ 2 Department of Management and Innovation Systems, University of Salerno, 84084 Salerno, Italy \\ * Correspondence: alhelou@tishreen.edu.sy (H.H.A.); psiano@unisa.it (P.S.)
}

Citation: Haes Alhelou, H.; Siano, P. Special Issue on Advances and Technologies in High Voltage Power Systems Operation, Control, Protection, and Security. Appl. Sci. 2021, 11, 274. https://doi.org/ 10.3390/app11010274

Received: 18 December 2020 Accepted: 28 December 2020 Published: 30 December 2020

Publisher's Note: MDPI stays neutral with regard to jurisdictional clai$\mathrm{ms}$ in published maps and institutional affiliations.

Copyright: (C) 2020 by the authors. Licensee MDPI, Basel, Switzerland. This article is an open access article distributed under the terms and conditions of the Creative Commons Attribution (CC BY) license (https:// creativecommons.org/licenses/by/ $4.0 /)$.

\section{Introduction}

The electrical demands in several countries around the world are increasing due to the huge energy requirements of prosperous economies and the human activities of modern life. In order to economically transfer electrical powers from generation-side to demand-side, these powers need to be transferred at high-voltage levels through suitable transmission systems and power substations. To this end, high-voltage transmission systems and power substations are in demand. Actually, they are at the heart of interconnected power systems, in which any faults might lead to unsuitable consequences, abnormal operation situations, security issues, and even power cuts and blackouts. In order to cope with the everincreasing operation and control complexity and security in interconnected high-voltage power systems, new architectures, concepts, algorithms, and procedures are essential. This special issue aims at encouraging researchers to address the technical issues and research gaps in high-voltage transmission systems and power substations in modern energy systems.

\section{Published Papers}

This special issue contains 10 highly qualified papers related to the latest advances and technologies in Power Systems Operation, Control, Protection, and Security. In what follows, each paper published in this special issue is introduced briefly by highlighting its main contributions. Authors in [1] have proposed a novel very fast transient overvoltage (VFTO) suppression method with great prospects in engineering, called the spiral tube damping busbar. The paper results showed that the improved damping busbar has a significant suppressing effect on the amplitude and the frequency of very fast transient overvoltage.

In [2], an adaptive ensemble square root Kalman filter (AEnSRF) has been proposed, in which the ensemble square root filter (EnSRF) and Sage-Husa algorithm are utilized to estimate measurement noise online. Simulation results obtained by applying the proposed method showed that the estimation accuracy of AEnSRF is better than that of ensemble Kalman filter (EnKF), and AEnSRF can track the measurement noise when the measurement noise changes.

Authors in [3] have presented a transient electromagnetic method (TEM) to determine grounding grid orientation without excavation. Unlike the existing pathological solutions, TEM does not enhance the surrounding electromagnetic environment. A secondary magnetic field as a consequence of induced eddy currents is subjected to inversion calculation. A digital simulator has been proposed in [4] that enables the dynamic testing of protective relays without using any steady test and expensive real-time simulators. This simulator includes both external waveform imports and internal waveform generation functions.

In [5], authors presented a comparative study on mother wavelets using a fault type classification algorithm in a power system. The study aims to evaluate the performance of the protection algorithm by implementing different mother wavelets for signal analysis and 
determines a suitable mother wavelet for power system protection applications. An online multiprocessor scheduling multiprocessor with bounded speed (MBS) has been proposed in [6]. The comparative analysis shows that the multiprocessor with bounded speed (MBS) outperforms other algorithms. The competitiveness of MBS is the least to date.

In [7], a new hybrid control algorithm for the cascaded modular multilevel converter has been presented. The Harris hawk's optimization ( $\mathrm{HHO}$ ) and atom search optimization (ASO) are used to optimally design the controller of the hybrid modular multilevel converters (MMC). This study in [8] has focused on one such application. In this proposed work, a direct current (DC)-based intermediate DC-DC power converter (i.e., a modified LUO (M-LUO) converter) is used to extricate the availability of power in the high range from the PV array.

Further to the above mentioned research papers, this special issues contains a case study. The case study in [9] applied laser-induced breakdown spectroscopy (LIBS) to analyze contamination on insulator surfaces. Moreover, a review paper [10] has also been published in this special issue. The review paper in [10] has addressed the existing approaches attending to cyber-physical security in power systems from a microgrid-oriented perspective.

Funding: This research received no external funding.

Acknowledgments: This issue would not have been possible without the help of a variety of talented authors, professional reviewers, and the dedicated editorial team of Applied Sciences. Thank you to all the authors and reviewers for this opportunity. Finally, thanks to the Applied Sciences editorial team.

Conflicts of Interest: The authors declare no conflict of interest.

\section{References}

1. Almenweer, R.A.; Su, Y.-X.; Xixiu, W. Numerical Analysis of a Spiral Tube Damping Busbar to Suppress VFTO in 1000 kV GIS. Appl. Sci. 2019, 9, 5076. [CrossRef]

2. Nan, D.; Wang, W.; Wang, K.; Mahfoud, R.J.; Haes Alhelou, H.; Siano, P. Dynamic State Estimation for Synchronous Machines Based on Adaptive Ensemble Square Root Kalman Filter. Appl. Sci. 2019, 9, 5200. [CrossRef]

3. Qamar, A.; Ul Haq, I.; Alhaisoni, M.; Qadri, N.N. Detecting Grounding Grid Orientation: Transient Electromagnetic Approach. Appl. Sci. 2019, 9, 5270. [CrossRef]

4. Kim, J.; Cho, G.-J.; Kim, J. Development of Railway Protective Relay Simulator for Real-Time Applications. Appl. Sci. 2020, 10, 191. [CrossRef]

5. Pothisarn, C.; Klomjit, J.; Ngaopitakkul, A.; Jettanasen, C.; Asfani, D.A.; Negara, I.M.Y. Comparison of Various Mother Wavelets for Fault Classification in Electrical Systems. Appl. Sci. 2020, 10, 1203. [CrossRef]

6. Singh, P.; Khan, B.; Mahela, O.P.; Haes Alhelou, H.; Hayek, G. Managing Energy Plus Performance in Data Centers and Battery-Based Devices Using an Online Non-Clairvoyant Speed-Bounded Multiprocessor Scheduling. Appl. Sci. 2020, $10,2459$. [CrossRef]

7. Diab, A.A.Z.; Ebraheem, T.; Aljendy, R.; Sultan, H.M.; Ali, Z.M. Optimal Design and Control of MMC STATCOM for Improving Power Quality Indicators. Appl. Sci. 2020, 10, 2490. [CrossRef]

8. Darcy Gnana Jegha, A.; Subathra, M.S.P.; Manoj Kumar, N.; Subramaniam, U.; Padmanaban, S. A High Gain DC-DC Converter with Grey Wolf Optimizer Based MPPT Algorithm for PV Fed BLDC Motor Drive. Appl. Sci. 2020, 10, 2797. [CrossRef]

9. Lu, S.; Wang, X.; Wang, T.; Qin, X.; Wang, X.; Jia, Z. Analysis of Salt Mixture Contamination on Insulators via Laser-Induced Breakdown Spectroscopy. Appl. Sci. 2020, 10, 2617. [CrossRef]

10. Canaan, B.; Colicchio, B.; Ould Abdeslam, D. Microgrid Cyber-Security: Review and Challenges toward Resilience. Appl. Sci. 2020, 10, 5649. [CrossRef] 